\title{
Human Sleep and Its Disorders
}




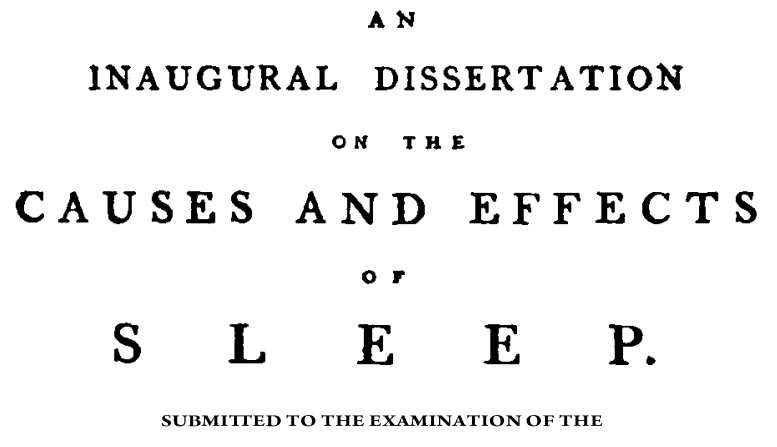

REV. JOHN EWING, S. T. P. PROVOST,

T $\mathbf{E}$

TRUSTEES AND MEDICAL PROFESSORS

O $\mathbf{T}$ H E

UNIVERSITY OF PENNSYLVANIA,

ON THE SEVENTEENTH DAY OF MAT, 1796,

FOR THE DEGRE OF

D O C T O R OF ME D I I N E.

By THOMAS BALL, OF VIRGINi,

MEMER OP THE PHILADELPHA MEDICAL SOCIETT.

Tird Nature's fweet Reftorer-Balmy Supp!

Youmo.

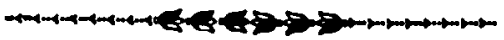

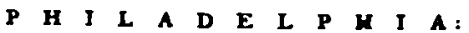

M.DCC. XCV

Title page of a dissertation on sleep written by Thomas Ball, an 18th century American physician. This fascinating work contains comments on such subjects as the effectiveness of hypnotics and causes of excessive sleepiness. (Courtesy of the Library of Congress) 


\section{Human Sleep and Its Disorders}

Wallace B. Mendelson, J. Christian Gillin, and Richard Jed Wyatt

National Institute of Mental Health

Bethesda, Maryland 
Library of Congress Cataloging in Publication Data

Mendelson, Wallace B

Human sleep and its disorders.

Bibliography: p.

Includes index.

1. Sleep disorders. 2. Sleep. 3. Physiology, Pathological. I. Gillin, J. Christian, joint author. II. Wyatt, Richard Jed, joint author. III. Title. [DNLM: 1. Sleep. 2. Sleep disorders. 3. Pharmacology. WM188 M537h]

RC547.M46

$616.8 ’ 49$

$76-48064$

ISBN-13: 978-1-4684-2291-7

The authors have written this as private individuals.

Views expressed here do not necessarily reflect those of the Public Health Service or the National Institute of Mental Health.

() 1977 Plenum Press, New York

Softcover reprint of the hardcover 1st edition 1977

A Division of Plenum Publishing Corporation 227 West 17 th Street, New York, N.Y. 10011

All rights reserved

No part of this book may be reproduced, stored in a retrieval system, or transmitted, in any form or by any means, electronic, mechanical, photocopying, microfilming, recording, or otherwise, without written permission from the Publisher 
In Memoriam

Robert A. Woodruff 


\section{Preface}

In this book we trace the development of several major themes in sleep research, from the first formal description of REM sleep in the early 1950s through the present. Chapter 1 provides those less familiar with this area with a perspective on the many possible ways to examine sleep. Chapter 2 describes in detail a major viewpoint of this book: that observations of pharmacological interventions affecting the neurotransmitters may aid in the understanding of sleep regulation. The remainder of the book is devoted to endocrine systems related to sleep (chap. 3 ) and to the contribution of sleep research to the understanding of various pathological states (chaps. 4-7). The areas of investigation open to those who wish to understand sleep are much broader than the traditional problems of insomnia and narcolepsy. Such disorders as depression, schizophrenia, and alcoholism have long been associated with disordered sleep. Our search for an understanding of the latter phenomena may clarify the nature of these conditions.

We have emphasized the study of human sleep. There are, of course, some scientific disadvantages to this approach. Because of ethical considerations, we obviously cannot, and do not wish to, employ the invasive procedures of the animal laboratory. Hence our inferences must often be indirect, and we may sometimes be observing epiphenomena, rather than the physiologic events themselves. On the other hand, there are several unique advantages to studying human sleep. First of all, sleep has a dual nature: It can be seen as both a physiological function and a subjective experience. In order to study the interworkings of these two phenomena, we must necessarily deal with humans. Second, it is our intention that our studies will ultimately be useful in solving human problems. In the absence of adequate 
animal models, we must study such conditions as the affective disorders and schizophrenia in persons suffering from them. Third, there is a technical advantage. The human REM-nonREM cycle lasts approximately 90 minutes, much longer than that of most laboratory animals. We are becoming more and more convinced that it is useful to study the effects of drugs that are infused briefly at different points in the sleep cycle. We also wish to examine substances in the blood that may appear in a specific stage of sleep. This can only be done when the cycle is long enough to be broken down into its constituent parts, as is the case in the human REM-nonREM cycle.

Finally, a few comments about our method of presentation are in order. We have tried to write in a manner that is understandable to the student as well as the professional researcher. For this reason, we have provided a section at the beginning of each chapter that outlines the basic concepts in the field. (In chapter 7, for example, we begin by briefly describing the symptoms and natural history of depressive disorders.) We have also tried to avoid giving the text a sedative quality of its own, which is often the result of narrating the results of one experiment after another. Since it is important that this information be available, however, we have made a series of tables describing the data from all the studies in a given area. In the text, we have emphasized the interplay of ideas derived from these studies. One approach that we found particularly useful was to determine the criteria needed to confirm or refute a hypothesis (e.g., that the secretion of a hormone is related to the occurrence of a sleep stage), and to determine how well these criteria have been met. Finally, we have tried to convey to the reader the sense of excitement we have experienced in studying the nature of sleep, a phenomenon both universal and exceedingly mysterious.

We wish to recognize the people who inspired and supported our work over the years: Drs. Frederick Snyder, William Bunney, Robert Cohen, Robert A. Woodruff, Donald W. Goodwin, Eli Robins, Irwin W. Feinberg, William Dement, and Alan Hobson.

In particular, we would like to thank Drs. Donald W. Goodwin, Lawrence S. Jacobs, and James F. Leckman for their valuable suggestions regarding various portions of this book. The responsibility for all statements in the text, however, lies with the authors.

Bethesda, Maryland and

Washington, D.C.
Wallace B. Mendelson J. Christian Gillin RICHARD Jed Wyatt 


\section{Contents}

1 An Introduction to Sleep Studies $\ldots \ldots \ldots \ldots \ldots \ldots \ldots \ldots \ldots$

Techniques of Human Sleep Studies .................. 3

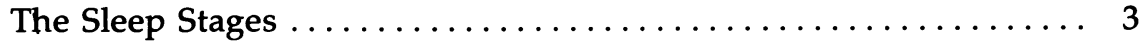

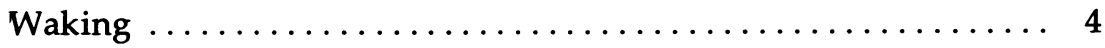

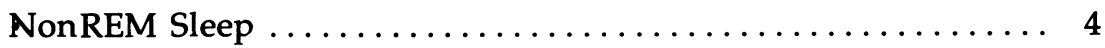

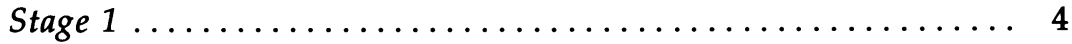

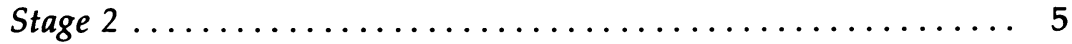

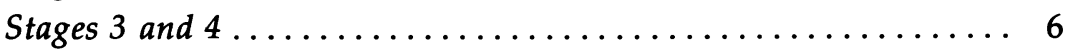

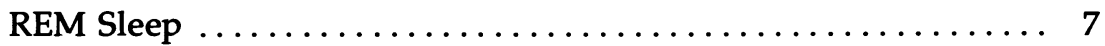

The REM-NonREM Cycle $\ldots \ldots \ldots \ldots \ldots \ldots \ldots \ldots \ldots \ldots \ldots .7$

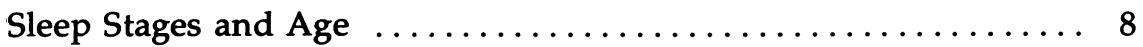

Effects of Temporal Variables on Sleep $\ldots \ldots \ldots \ldots \ldots \ldots \ldots \ldots$

Physiological Variables Related to the Sleep Stages $\ldots \ldots \ldots \ldots 11$

Sleep Deprivation ............................. 11

Total Sleep Deprivation ....................... 11

Selective Sleep Stage Deprivation ................... 13

Natural Long, Short, and Variable Sleepers.............. 14

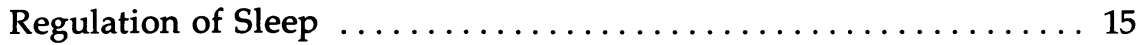

Passive versus Active Regulation .................... 15

The Neurotransmitters ........................ 17

Pharmacologic and Anatomic Approaches .............. 17

Neurotransmitters and the REM-NonREM Cycle .......... 18

Neurotransmitters and Arousal ..................... 19 
Circulating Humors and Sleep $\ldots \ldots \ldots \ldots \ldots \ldots \ldots \ldots \ldots$

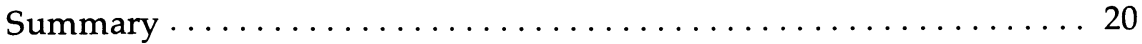

2 A Pharmacologic Approach to Sleep Studies............ 21

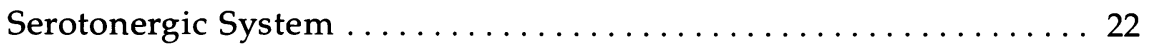

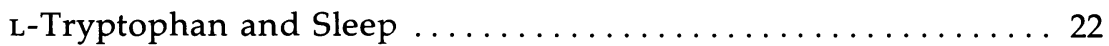

Effects of Administration on Sleep ................... 22

Metabolic Considerations ......................... 25

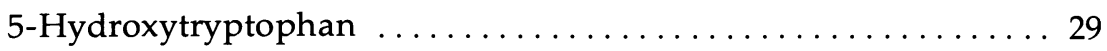

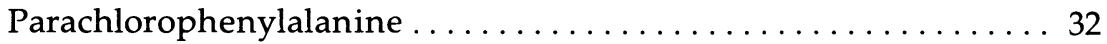

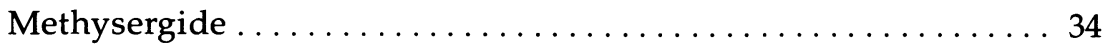

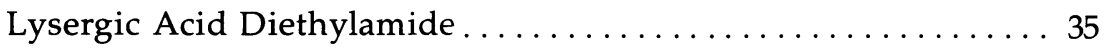

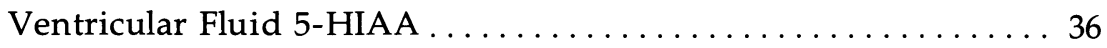

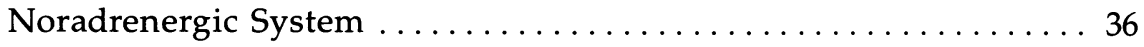

L-Dihydroxyphenylalanine (L-DOPA) $\ldots \ldots \ldots \ldots \ldots \ldots \ldots \ldots \ldots \ldots \ldots \ldots \ldots$

Effects on REM Sleep .......................... 36

Effects on NonREM Sleep ....................... 42

Threo-dihydroxyphenylserine (DOPS) .............. 42

Alpha-Methyl-Paratyrosine (AMPT) and Alpha-Methyl-

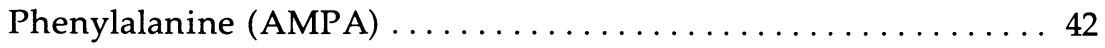

Alpha-Methyl-DOPA $\ldots \ldots \ldots \ldots \ldots \ldots \ldots \ldots \ldots \ldots \ldots \ldots \ldots \ldots \ldots$

Pimozide ................................ 45

Adrenergic Receptor Blockers $\ldots \ldots \ldots \ldots \ldots \ldots \ldots \ldots \ldots, 45$

Other Drugs Influencing Amines ................... 45

Monoamine Oxidase Inhibitors .................... 45

Tricyclic Antidepressants and Blockers of Amine Re-uptake . . . . . 48

Reserpine .............................. 49

Debrisoquine .............................. 49

Amphetamines.............................. 50

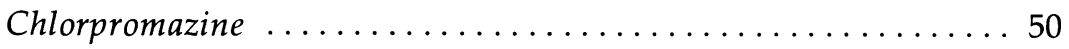

Effect of Diets Deficient in Catecholamine Precursors ........ 51

Metabolites of Norepinephrine and Dopamine in the CSF ..... 51

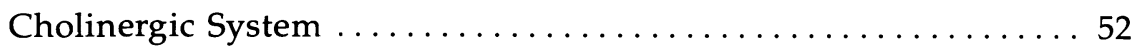

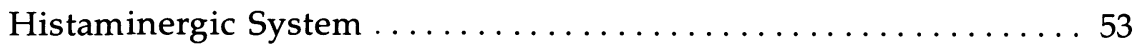




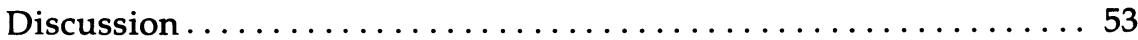

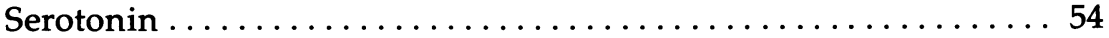

Serotonin or a Metabolite? ......................... 54

Relation to REM Sleep............................ 54

Relation to NonREM Sleep ........................ 55

Noradrenergic System.......................... 58

Norepinephrine or a Precursor? ................. 58

Effects on REM Sleep ........................... 59

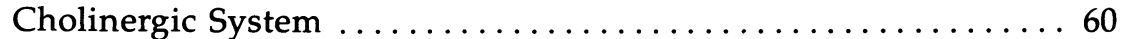

Histaminergic System . . . . . . . . . . . . . . . . . 60

Interaction between Transmitters $\ldots \ldots \ldots \ldots \ldots \ldots \ldots \ldots 60 \ldots$

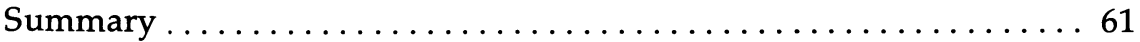

3 Neuroendocrinology and Sleep $\ldots \ldots \ldots \ldots \ldots \ldots \ldots \ldots$

Basic Concepts in Neuroendocrinology $\ldots \ldots \ldots \ldots \ldots \ldots \ldots 64$

Growth Hormone ................................. 67

Sleep-Related GH Secretion in Disease States ............ 73

Effects of Injections of GH on Sleep ................ 75

The Pituitary-Adrenal Axis ....................... 76

Relation to Sleep-Waking Cycle $\ldots \ldots \ldots \ldots \ldots \ldots \ldots \ldots \ldots \ldots \ldots$

Sleep-Related Cortisol Secretion in Disease States .......... 78

Effects of ACTH and Cortisol on the Sleep Stages .......... 80

Prolactin..................................... 82

Relation of PRL Secretion to Other Hormones ........... 83

Effects of Drugs on Sleep-Related Prolactin Secretion ......... 83

Follicle-Stimulating Hormone and Luteinizing Hormone . . . . . . 84

Relation of LH and FSH Secretion to Sleep ............. 84

Relation of Testosterone Secretion to Sleep . . . . . . . . . . 85

Effects of Sex Hormones on Sleep ................... 86

-Sleep-Related Secretion in Disease States . . . . . . . . . . 87

Thyroid-Stimulating Hormone $\ldots \ldots \ldots \ldots \ldots \ldots \ldots \ldots \ldots . \ldots 8$

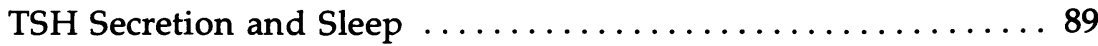

Sleep in Hyper- and Hypothyroidism . . . . . . . . . . . . . 89

CNS Actions of TRH ........................ 90 
Antidiuretic Hormone ........................ 90

ADH Secretion during Sleep........................ 91

Effects of ADH on Sleep ....................... 91

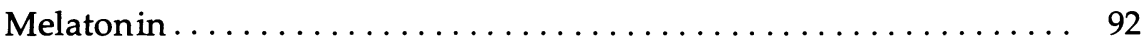

Effects of Melatonin on Sleep ................... 93

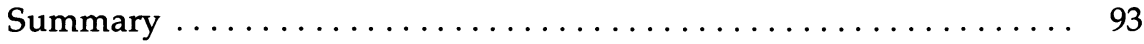

4 Narcolepsy and Diseases of Excessive Sleep ............ 95

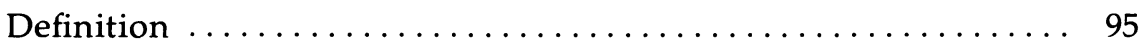

Sleep Attacks $\ldots \ldots \ldots \ldots \ldots \ldots \ldots \ldots \ldots \ldots \ldots \ldots \ldots . \ldots \ldots$

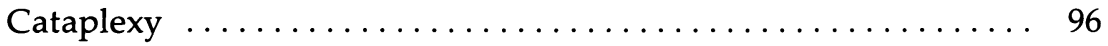

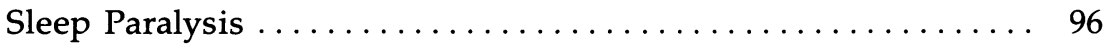

Hypnogogic and Hypnopompic Hallucinations .......... 98

Natural History $\ldots \ldots \ldots \ldots \ldots \ldots \ldots \ldots \ldots \ldots \ldots \ldots . \ldots \ldots$

Epidemiology and Genetics ..................... 99

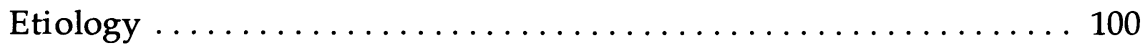

Narcolepsy-Cataplexy ......................... 100

Secondary Narcolepsy $\ldots \ldots \ldots \ldots \ldots \ldots \ldots \ldots \ldots \ldots \ldots \ldots 10 \ldots \ldots$

Other Disorders of Excessive Daytime Sleep . . . . . . . . . . 102

Independent Narcolepsy or NonREM Narcolepsy . . . . . . . . 102

Obstructive Sleep Apnea Syndrome $\ldots \ldots \ldots \ldots \ldots \ldots \ldots . \ldots 103$

Narcolepsy with Sleep Apnea ...................... 103

'Hypersomnia with Automatic Behavior ............... 104

Hypersomnia with Sleep Drunkenness ................ 104

Excessive Daytime Sleepiness Associated with Known

Organic Disease ................................... 104

Excessive Daytime Sleepiness in Depression .............. 104

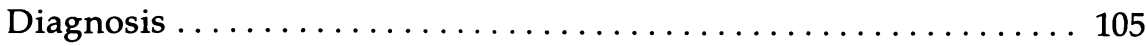

Pharmacotherapy of Narcolepsy ..................... 105

Stimulants .................................... 105

Tricyclic Antidepressants ....................... 106

Monoamine Oxidase Inhibitors. . . . . . . . . . . 106

Methysergide ............................ 107

Other Pharmacotherapies ....................... 107

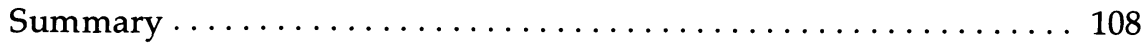


5 Clinical Studies of Insomnia . . . . . . . . . . . . . . 109

Normal Sleep . . . . . . . . . . . . . . . . . . . . . 110

Incidence of Insomnia $\ldots \ldots \ldots \ldots \ldots \ldots \ldots \ldots \ldots \ldots \ldots \ldots \ldots \ldots$

Kinds of Insomnia $\ldots \ldots \ldots \ldots \ldots \ldots \ldots \ldots \ldots \ldots \ldots \ldots \ldots \ldots$

Tentative List of Causes of Insomnia . . . . . . . . . . . . 112

Psychogenic ............................ 112

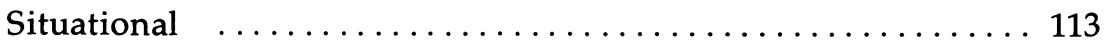

Alterations of Normal Activity-Rest Cycle . . . . . . . . . . . . . 113

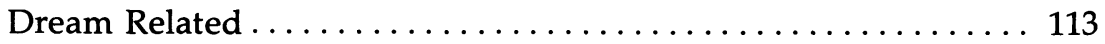

Sleep Apnea $\ldots \ldots \ldots \ldots \ldots \ldots \ldots \ldots \ldots \ldots \ldots \ldots \ldots \ldots$

Restless Legs Syndrome . . . . . . . . . . . . . . . . . . . 114

Nocturnal Myoclonus . . . . . . . . . . . . . . . . . . . . . . 114

Oversleeping ............................ 114

Drug Related ........................... 114

Neurological ............................ 115

Secondary to or Accompanying a Medical Illness . . . . . . . 115

Sleep Induction . . . . . . . . . . . . . . . . . . . 115

Alcohol . . . . . . . . . . . . . . . . . . . . . . . . . 117

Benzodiazepines .......................... 117

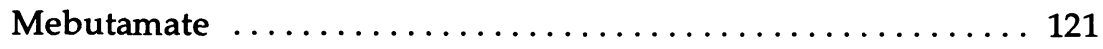

Barbiturates ............................ 121

Chloral Hydrate ........................... 121

Glutethimide ........................... 121

Methaqualone ........................ 121

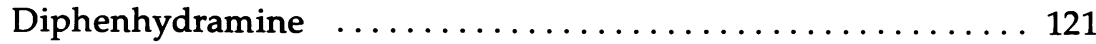

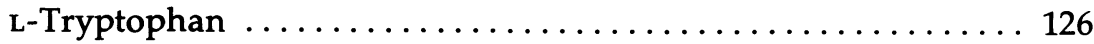

Electrosleep ............................ 126

An Approach to Patients Who Complain of Insomnia . . . . . . . 126

6 Alcohol, Alcoholism, and the Problem of Dependence ..... 131

Animal Studies $\ldots \ldots \ldots \ldots \ldots \ldots \ldots \ldots \ldots \ldots \ldots \ldots \ldots$

Ethanol and the Sleep EEG of Animals . . . . . . . . . . 131

Ethanol and Behavioral Measures of Sleep . . . . . . . . . . 132

Ethanol and Possible Neurotransmitters .............. 133

Animal Studies of Spontaneous Ethanol Selection . . . . . . . 135 
Ethanol in Normal Human Subjects ................... 135

Effects of Ethanol on Chronic Alcoholics ................. 139

Sleep in "Dry" Alcoholics . . . . . . . . . . . . . . . . . . . . 139

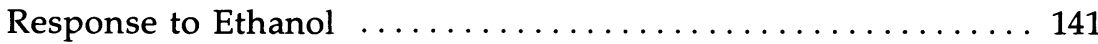

Sleep during Acute Withdrawal ................... 141

Issues Raised by Observations of the REM Sleep Rebound . . . . . 142

Experimental Therapies .......................... 144

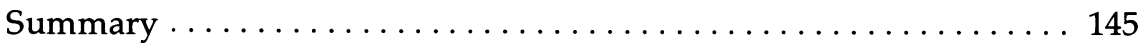

7 Affective Disorders and Schizophrenia $\ldots \ldots \ldots \ldots \ldots \ldots 147$

Basic Definitions .............................. 148

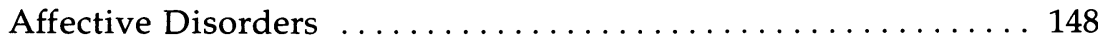

Schizophrenia ................................ 149

Studies of Sleep in Depressed Patients . . . . . . . . . . . . 150

Comparative Studies ........................... 150

Longitudinal Studies of Depressed Patients . . . . . . . . . . 159

Sleep of Depressed Patients in Remission ............... 163

Chemical Correlates of Sleep in Depression .............. 164

Further Sleep Studies in Bipolar Illness ................ 165

Sleep during the Switch Process in Manic-Depressive Illness . . 167

Experimental Deprivation of Sleep in Depression .......... 173

Effects of REM Sleep Deprivation on Depression .......... 177

Effects of Antidepressant Medication and Lithium Salts on

Human Sleep ............................. 178

Concluding Comments on Affective Disorders .......... 185

Sleep Studies in Schizophrenia .................... 188

Cross-Sectional Studies of Schizophrenia . . . . . . . . . . 189

Longitudinal Studies of Sleep in Schizophrenia ........... 195

Experimental REM Deprivation in Schizophrenia .......... 196

Experimental Sleep Deprivation in Schizophrenia ........... 204

Effects of Neuroleptics on Sleep .................... 205

Concluding Remarks about Sleep in Schizophrenia ........ 210

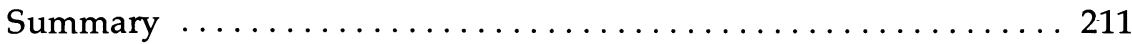

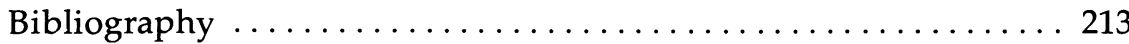

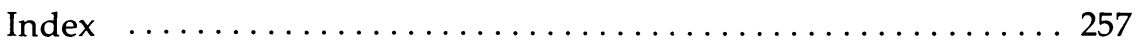

